\title{
Publications of the International Astronomical Union as biographical sources
}

\author{
Wolfgang R. Dick \\ Potsdam, Germany \\ email: wdick@astrohist.org
}

\begin{abstract}
Publications of the International Astronomical Union (IAU), such as Proceedings of IAU Symposia and Colloquia, contain biographical notes and papers as well as obituaries. Of great value are also the death announcements in the IAU Information Bulletins that contain the only biographical data known for about 200 astronomers. The kind of data given in these announcements varied over time. References to these data can be found in the Biographical Index of Astronomy. Recently the printed announcements were replaced by entries in the on-line IAU membership database.
\end{abstract}

Keywords. obituaries, biographies, bio-bibliography, IAU Proceedings, IAU Information Bulletins

\section{Introduction}

Astronomy, as a science, and the work of the International Astronomical Union, are based on activities of astronomers. To study the history of astronomy and of the IAU, it is therefore necessary also to consider biographies of astronomers.

In a broader sense, all publications contain biographical data. They are part of the oeuvre of their author(s), and yield information about the authors' fields of work and their affiliations. However, in what follows we regard biographical publications in a narrower sense, i.e., those that were written as biographies, or which contain biographical data like dates of birth or death.

This paper was written in the context of the Biographical Index of Astronomy (BIA), the first edition of which appeared in 2005 followed by the enlarged second edition in 2017 (Brüggenthies and Dick 2017). This inventory lists, for 29,500 astronomers and other persons with relation to astronomy, their dates of life as well as biographical sources (books, papers, encyclopaedic entries, obituaries, etc.). Besides professional and amateur astronomers ( $50 \%$ and $10 \%$ of entries, respectively), the index contains numerous physicists $(20 \%)$, mathematicians (12\%), geodesists, geologists, geophysicists, meteorologists, globe and instrument makers, pioneers of space flight, patrons of astronomy, and others. For this bio-bibliographical list, also numerous IAU publications were indexed.

\section{Biographical papers in IAU publications}

Some of the IAU Symposia and Colloquia were devoted to astronomers, and these proceedings contain a biographical paper about the honoured person (e.g., Wild 1980) or at least a dedication or a paragraph in the foreword. In other cases one of the members of the Scientific Organising Committee passed away before the publication of the proceedings, and these contain an obituary. During some of the IAU conferences a session devoted to history was held, during which also biographical papers were presented and published in the proceedings (e.g., Dollfus 1988). 
Le Secrétaire Général a le regret d'annoncer le décès des membres de l'UAI dont les noms suivent:

Maria Alcina Braz (Brésil) - 24 Mai 1987

Nicholas Bobrovnikoff (USA) - 21 Mars 1988

Y.Palacios de Mottoni (Italie) - 9 Mai 1988

P.E. Elyasberg (URSS)- 30 Mars 1988

Walter Fricke (R.F.A.) - 21 Mars 1988

The General Secretary regrets to announce the following names of Members whose death has been reported to, and verified by, the Secretariat since IB 86 :

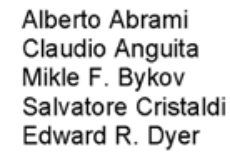

Alberto Abrami

Salvatore Cristald

Edward R. Dyer

\author{
The Union is saddened to learn of the deaths of the following members \\ and former members: \\ Jim Cohen, UK (1948-2006), past-president IAU Commission 50 \\ S.M. Hassan, Egypt (1937-2006), chairman Egyptian NCA \\ Vladimir Kourganoff, France (1912-2006) \\ Hugo E. Schwarz, Chile (1953-2006), president IAU Commission 50
}

The Union is saddened to learn that the following members and former members passed away, as far as reported to the IAU Secretariat:

KD ABHYANKAR (1928 - 2007), India 8 November 2007

Oliveira Grijo AN'TARES Kleber (1949 - 2009), Brazil, 6 March 2009

Kevin BEURLE (1956 - 2009), UK, 29 May 2009

Gianfranco BISIACCHI Giraldi (1947 - 2006), Mexico, 16 September 2006

Rolf BRAHDE (1918 - 2009), Norway, 25 May 2009

Figure 1. Death announcements of IAU members in the IAU Information Bulletins. The kind of data given varied over time. Top to bottom: (a) IAU IB No. 60, 1988; (b) No. 87, 2000; (c) No. 99, 2007; (d) No. 104, 2009.

In rare cases the IAU Information Bulletins contain obituaries of or reminiscences by IAU officers (e.g., Blaauw 1997; Minnaert et al. 1969). Some issues of newsletters of Commissions (e.g., of the former Commissions 26, 41, and 46) included obituaries of Commission members (e.g., Dommanget 2007).

Most of the biographical papers in conference proceedings are indexed in the bibliographic database of the SAO/NASA Astrophysics Data System (ADS), as are also some of the obituaries in the IAU Information Bulletin. However, from the examples given above, Minnaert et al. (1969) and Dommanget (2007) are missing in ADS, as well as many other such papers and all obituary or biographical notes in forewords to proceedings. One of the scopes of the Biographical Index of Astronomy is to point to these hidden sources, although the second edition is still incomplete in this respect. It contains 21 references to IAU Colloquia, 3 to IAU Symposia, and 10 to Commission Newsletters. The planned third edition will be more complete.

\section{Announcements of death}

Another biographical source are the announcements of death in the IAU Information Bulletins (IAU IB). In many cases, these contain birth and death dates. However, in numerous cases these dates are missing, but from the announcements it is at least known that a person has deceased before the publication date of the given Bulletin, although an exact year cannot be derived because the delay of the announcements was sometimes rather large. The amount of data given varies over time (Fig. 1) and seems to have 

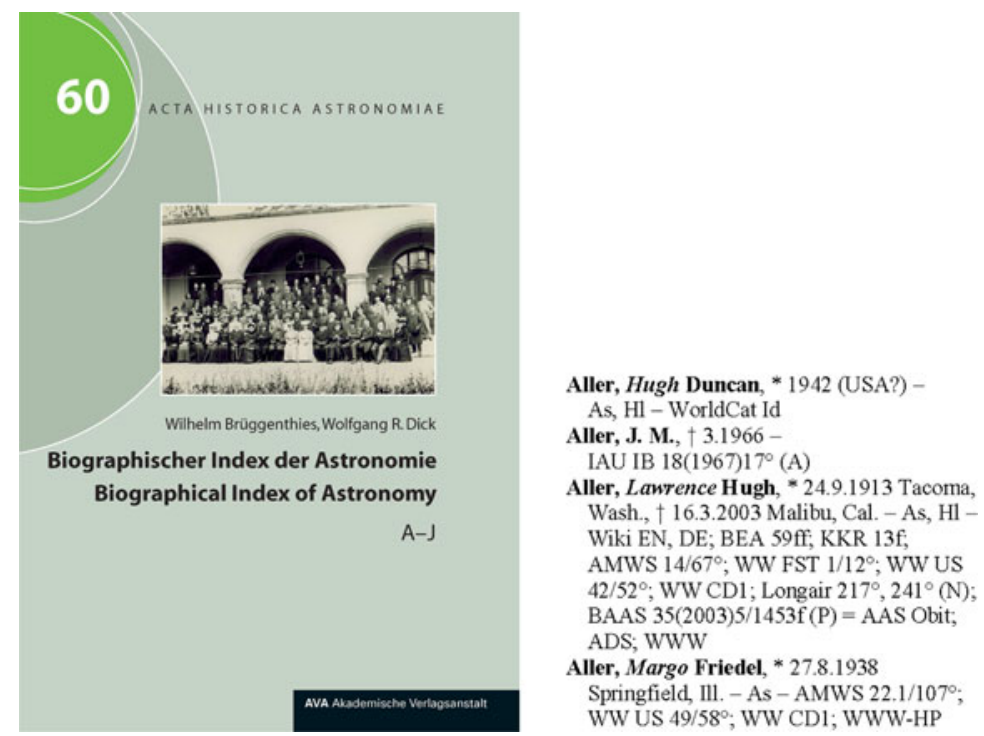

Figure 2. The Biographical Index of Astronomy (2017), containing bio-bibliographical data for 29,500 persons related to astronomy, among these numerous past and current IAU members. Left: (a) Cover page of the first of two volumes; right: (b) Entries for four IAU members. J.M. Aller is one of those for whom nothing could be found besides the death announcement in the IAU IB.

depended on the acting IAU General Secretary or the staff of the Secretariat. Naturally, the completeness of data could not be better than the completeness of the data received by the Secretariat, but unfortunately during certain periods the announcements contained names only and no life dates (Fig. 1b). It would be very useful to keep the original death notes received by the IAU Secretariat for historical studies because in many cases these contained more information than published in the IAU IB.

The death announcements are not indexed in ADS or elsewhere, and the only list of them is to be found in the Biographical Index of Astronomy (Fig. 2). For the second edition, all lists of deceased members in IAU IBs were compared with the entries in BIA. A large number of persons and data could thus be added. The second edition of BIA contains 623 references to IAU IBs; most of them refer to the announcements of death, although all those announcements that do not give additional information to biographies and obituaries, were omitted. In about 220 cases, the announcement in an IAU IB is the only biographical source for a given person (Fig. 2b). Therefore, these IAU publications are very valuable sources of information.

However, the comparison of the announcements with other sources has also revealed that the dates of birth and death are not very reliable. A typical mistake is a year of birth wrong by 1 year. I guess that in these cases the year of birth was derived from the age at death, but this method cannot always give an exact year. Also the dates of death are not always correct. One should keep this in mind when using the data. There were also a couple of cases when the passing of an IAU member was announced by mistake, but was later recalled. It cannot be excluded, though, that in one or more cases such incorrect announcements may not have been set right.

Before 1959, when the first IAU IB appeared, death announcements were published only in IAU Transactions. Concerning completeness and reliability of dates these announcements are comparable with those in the IAU IBs. However, they are less important because for most IAU members of the first decades biographies and obituaries are available. Therefore, the BIA contains only 24 references to IAU Transactions. 


\section{Information on deceased members in the IAU membership database}

The last IAU Information Bulletin was No. 112 that appeared in 2013. Since then, announcements of the death of IAU members can be found only in the IAU membership database $\nmid$ and (without any life dates) in the IAU Transactions. Recently, the IAU Secretariat started to add short obituaries, portraits and links to external obituaries of deceased members, as far as available, which is a great advantage over the former short announcements in IAU IBs. Unfortunately, for deceased members only the years of birth and death are given, differently to the IAU IBs where complete dates were often indicated. This is a shortcoming when no other sources of information are available. It would be helpful for the historiography of astronomy to return to the policy of the IAU IBs with respect to dates of lives of deceased members.

The Secretariat also started to add members who died before the database of current members was created. At this moment, in many cases life data for these members are still missing but will be added later.

Unfortunately, the IAU Secretariat is not always informed about the deaths of members by the National Committees, by institutions or members. Working on the Biographical Index of Astronomy, I found numerous IAU members who passed away several years ago, but were still listed as active or inactive members in the database. The Secretariat immediately corrected this when I informed them, so that the reason for the outdated entries is missing information from outside. Each IAU member who learns about the death of a colleague should check the IAU membership database to see whether the IAU Secretariat was already informed, and to write to the IAU members administration in the negative case. The Secretariat will also welcome obituaries (or links to necrologies) and portraits.

\section{Acknowledgements}

My thanks goes to Madeleine Smith-Spanier of the IAU Secretariat who does an excellent job in maintaining the IAU membership database and always very quickly adds the information on deceased members sent to her.

\section{References}

Blaauw, A. 1997, In memoriam: V.A. Ambartsumian. IAU Information Bulletin No. 79, p. v-vi Brüggenthies, W., Dick, W. R. 2017, Biographischer Index der Astronomie / Biographical Index of Astronomy. 2 vols. Leipzig: AVA - Akademische Verlagsanstalt, (Acta Historica Astronomiae; vol. 60)

Dollfus, A. 1988, Eugène Antoniadi (1870-1944) and Planetary Observation. In: Stargazers. The Contribution of Amateurs to Astronomy. Proceedings of IAU Colloqoquium 98, 20-24 June 1987. Storm Dunlop and Michèle Gerbaldi (eds.). Berlin, Heidelberg, New York: Springer-Verlag, p. 28-31

Dommanget, J. 2007, Omer Nys (1931-2007). International Astronomical Union Commission 26 (Double Stars), Information Circular No. 162 (June 2007)

Minnaert, M., Oort, J. H., Oosterhoff, P. Th., Sadler, D. H., Swings, P., Van Biesbroeck, G. A. 1969, Reminiscences of the International Astronomical Union. IAU Information Bulletin No. 22 , p. $3-10$

Wild, J. P. 1980, The S. F. Smerd Memorial Lecture: The Sun of Stefan Smerd. In: Radio Physics of the Sun, Proceedings of IAU Symposium No. 86, held 7-10 August 1979 in College Park, MD. M. R. Kundu and T. E. Gergely (eds.). Dordrecht: D. Reidel Publishing Co., p. 5-21

$\dagger$ https://www.iau.org/administration/membership/individual/ 